\title{
Quadrature Phase Shift Keying (QPSK) Modulator Design using Multi-Port Network in Multilayer Microstrip-Slot Technology for Wireless Communication Applications
}

\author{
Norhudah SEMAN, Siti Nor Ain MOHAMED GHAZALI \\ Wireless Communication Centre (WCC), Universiti Teknologi Malaysia, 81310 UTM Johor Bahru, Johor, Malaysia \\ huda@fke.utm.my, ain_ghazaly@yahoo.com
}

\begin{abstract}
The design of the quadrature phase shift keying (QPSK) modulator by using a multi-port network is proposed in this article for the use in wireless communication applications. The multi-port network is in the form of multilayer microstrip-slot technology. This multi-port network is composed of three 3- $d B$ rectangular-shaped directional couplers with virtual stubs and an equal power division divider with in-phase characteristic. The design is performed by applying a full-wave electromagnetic simulation software, CST Microwave Studio (CST MWS). Keysight's Advanced Design System (ADS) is applied in analyzing and evaluating the QPSK constellation of the proposed modulator. This comparatively small size of proposed design has been fabricated, and its wideband performance of 2 to $6 \mathrm{GHz}$ is verified.
\end{abstract}

\section{Keywords}

Coupler, modulator, multi-port, power divider, QPSK, wireless

\section{Introduction}

The massive demand towards high-speed wireless communication connection seems will never end, even with the recent deployment of $4^{\text {th }}$ Generation cellular system $(4 \mathrm{G})$. Where, wireless technology starts to view toward $5^{\text {th }}$ Generation $(5 \mathrm{G})$ with the concept on communication that not limited between humans but additionally the machine-to-machine and vehicle-to-vehicle, which anticipated in the year 2020. This strong demand of the 24/7 ubiquitously high-speed connectivity to anything at anytime leads to excessive challenge to the researchers and engineers involving RF and microwave components, antenna and network planning. The vital design feature in any front-end configuration of a wireless communication system is a mixer-based approach such in modulator, which been used to modulate and demodulate the signal.
To be in the active state, the mixer-based modulator design consisting of active devices requires a sort of positive biasing. This requirement may lead to the complexity of modulator design. The complexity can be lessened by implementing multi-port network to replace the mixerbased design [1]. This network is only constructed by passive devices such as coupler, power divider and/or H-hybrid. Therefore, there is no requirement of biasing circuit. Furthermore, this device has an ability to measure two complex signals. This feature can be further applied in the purpose of signal modulation such as a quadrature phase shift keying (QPSK) and 16-quadrature amplitude modulation (16-QAM) as reported in [1-5].

Previous bulky, complex and narrowband multi-portbased modulator gave motivation to design a compact and simple multi-port modulator with low manufacturing cost and good wideband performance. The reported narrowband designs utilizing three couplers and one power divider in [1-4] consider only single operating frequency of $60,2.4$, 2.5 and $7.5 \mathrm{GHz}$, accordingly. Meanwhile, there are improved bandwidth performances proposed in [5] and [6] with almost similar operating frequency of $3.1-4.8 \mathrm{GHz}$ and 3-5 GHz, accordingly. Unfortunately, the bandwidth performance is still inadequate. Furthermore, the use of branch line couplers in the multi-port network in [2-4] and [5] lead to a large size device, which not favorable in the current trend. Whilst, design in [6] is formed by the power divider and quadrature hybrid implemented using one and two substrates, respectively. The use of the different number of substrate may create a difficulty in integration with other circuits. Another design presented in [7] has considerable wideband performance from 4.5 to $9 \mathrm{GHz}$ with relatively small size. However, the presented QPSK constellation is only verified for selected frequency of 5, 6.5 and $8 \mathrm{GHz}$. Then, impressive miniaturization and wideband designs achieved by designing at millimeterwave region have been demonstrated in [8] and [9] with the operating frequency of $23-31 \mathrm{GHz}$ and $24-30 \mathrm{GHz}$, respectively. Nevertheless, these designs require high precision and high-end fabrication facility and measurement 
equipment, which may not be available in most research laboratories.

In this article, a QPSK modulator is proposed by implementing a multi-port network, which is constructed by three tight coupling rectangular-shaped couplers with virtual stubs and an in-phase power divider with equal power division. Multilayer microstrip-slot design approach is employed in the coupler and power divider design composing the multi-port to enhance the bandwidth performance. Multi-port's function to measure two complex signals' ratio can be achieved with the application of measured powers at the output ports [10]. CST Microwave Studio (CST MWS) is utilized to design and optimize the tight coupling coupler, in-phase power divider and multiport. Whilst, the evaluation on QPSK through the analysis of S-Paramaters is carried out via the use of Keysight's Advanced Design System (ADS) software. Then, the proposed QPSK modulator using the designed multi-port network is verified experimentally.

\section{Design of Quadrature Phase Shift Keying (QPSK) Modulator}

A signal modulator block diagram using a multi-port network in a communication transmitter can be illustrated as in Fig. 1(a). To function as a modulator, an input port of the multi-port is arranged for the local oscillator (LO). A series of power amplifier and transmitting antenna is fixed to one of the output ports. While, switchable loads are terminating the other output ports. The combination of switchable loads with certain impedance values determines the modulation state. The information signal can be modulated to any modulation scheme by the multi-port network relying on the termination used. The configuration of chosen multi-port network used in the purpose of this modulator design is formed by passive devices of three directional couplers with tight coupling of 3-dB (Q) and 3-dB in-phase power divider (D). By having impedance load connected to output ports of Port 4 to 7 , the detailed signal flows can be shown as in Fig. 1(b). The incident signals can be derived as the following equations:

$$
\begin{gathered}
b_{1}=b_{2}=\frac{c}{\sqrt{2}}, \\
b_{3}=-j \frac{c}{2 \sqrt{2}}\left(\Gamma_{4}+\Gamma_{5}\right), \\
b_{4}=-j \frac{c}{2 \sqrt{2}}\left(\Gamma_{6}+\Gamma_{7}\right)
\end{gathered}
$$

where, $c$ is the incident microwave signal from Port 1 and $\Gamma_{i}$ represent the reflection coefficient of load connected to output ports, where $i=4,5,6$ and 7. While, the reflected signals to power divider (D) are ideally equal to zero as expressed in (4):

$$
\begin{aligned}
& a_{1}=\frac{c}{2 \sqrt{2}}\left(\Gamma_{4}-\Gamma_{5}\right)=0, \\
& a_{2}=\frac{c}{2 \sqrt{2}}\left(\Gamma_{6}-\Gamma_{7}\right)=0 .
\end{aligned}
$$

Therefore, the modulated signal, $S_{2}$ at Port 2, which is also denoted as $d$ can be derived as equation (5):

$$
S_{2}=-j \frac{1}{4} S_{L O}(t)\left[\left(\Gamma_{4}+\Gamma_{5}\right)-j\left(\Gamma_{6}+\Gamma_{7}\right)\right]
$$

where $S_{L O}(t)$ is generated by the local oscillator (LO) which is denoted by $c$ in Fig. 1(b).

To achieve the purpose of QPSK modulation, the output ports are terminated by the switchable short and open load [4]. The four QPSK modulation states with the required reflection coefficient at output ports are listed in Tab. 1. These required reflection coefficients are realized through certain combination of termination of short and open load. The combination of switchable short and/or open-circuit terminations allows each modulation state to having phase difference of $90^{\circ}$.

This QPSK modulator is realized using multi-port network that is designed in a planar form of multilayer mi-
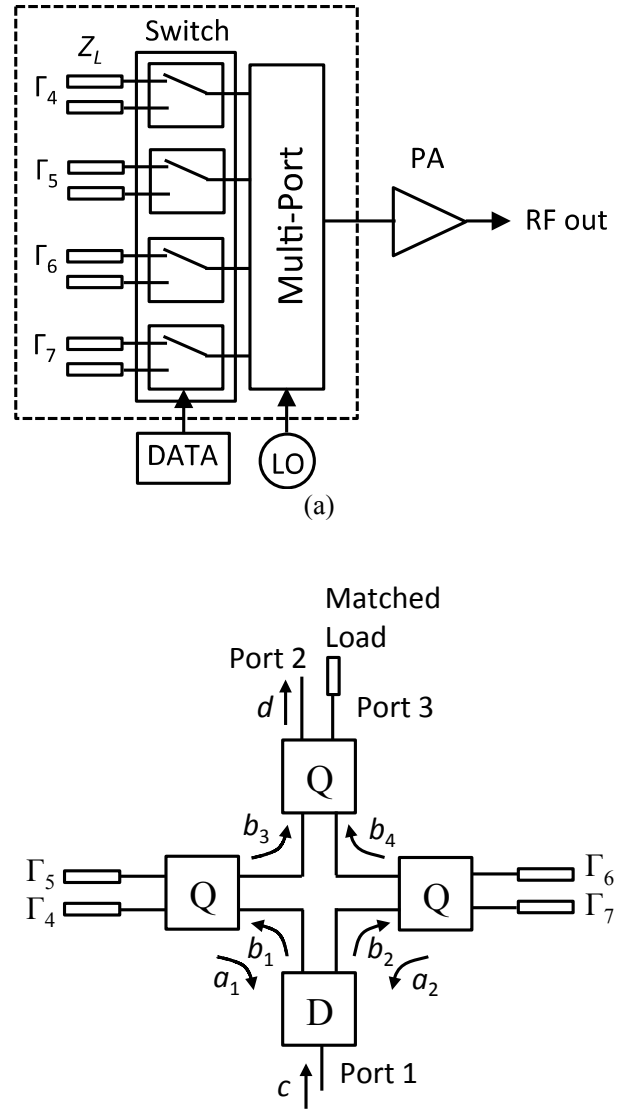

(b)

Fig. 1. Block diagram of (a) modulator using multi-port in transmitter and (b) multi-port configuration with signal flows. 
crostrip-slot technology implementing a hydrocarbon ceramic substrate of Rogers RO4003C with 3.38 relative permittivity and 0.027 loss tangent. The thickness of substrate and conductor coating are $0.508 \mathrm{~mm}$ and $17 \mu \mathrm{m}$, respectively. 3-dB rectangular-shaped directional coupler with virtual stubs and in-phase power divider with equal division are chosen to form the multi-port network.

\begin{tabular}{|c|c|c|c|c|c|c|c|c|c|}
\hline \multirow{2}{*}{$\begin{array}{c}\text { Modulation } \\
\text { state }(\mathrm{m})\end{array}$} & \multicolumn{6}{|c|}{$\begin{array}{c}\text { Reflection coefficient } \\
\text { of termination load }\end{array}$} & \multicolumn{4}{c|}{$\begin{array}{c}\text { Termination load at } \\
\text { output ports }\end{array}$} & \multirow{2}{*}{$\begin{array}{c}S_{2} \\
\text { (phase) }\end{array}$} \\
\cline { 2 - 10 } & $\Gamma_{4}$ & $\Gamma_{5}$ & $\Gamma_{6}$ & $\Gamma_{7}$ & $\mathrm{P}_{4}$ & $\mathrm{P}_{5}$ & $\mathrm{P}_{6}$ & $\mathrm{P}_{7}$ & \\
\hline 0 & 1 & 1 & 1 & 1 & $\mathrm{O}$ & $\mathrm{O}$ & $\mathrm{O}$ & $\mathrm{O}$ & $0^{\circ}$ \\
\hline 1 & 1 & 1 & -1 & -1 & $\mathrm{O}$ & $\mathrm{O}$ & $\mathrm{S}$ & $\mathrm{S}$ & $-90^{\circ}$ \\
\hline 2 & -1 & -1 & 1 & 1 & $\mathrm{~S}$ & $\mathrm{~S}$ & $\mathrm{O}$ & $\mathrm{O}$ & $90^{\circ}$ \\
\hline 3 & -1 & -1 & -1 & -1 & $\mathrm{~S}$ & $\mathrm{~S}$ & $\mathrm{~S}$ & $\mathrm{~S}$ & $180^{\circ}$ \\
\hline
\end{tabular}

Tab. 1. The required reflection coefficients and termination loads for QPSK modulation and its phase characteristic of modulated signal, $S_{2}$ (where, notation $\mathrm{O}$ and $\mathrm{S}$ are referring to open and short, respectively).

The generated CST layout and prototype of rectangular-shaped coupler with virtual short stubs are depicted in Fig. 2 and 3, respectively. This coupler as reported in [11] enhanced the return loss and isolation performance of initial three-section rectangular-shaped design in [12]. Where, the additional virtual short stub is attached to the top and bottom patch of middle section. The identical microstrip patches are broadside coupled by slot at middle layer of the common ground plane.

The designated 3-dB coupling coefficient can be accomplished by controlling the microstrip and slotline

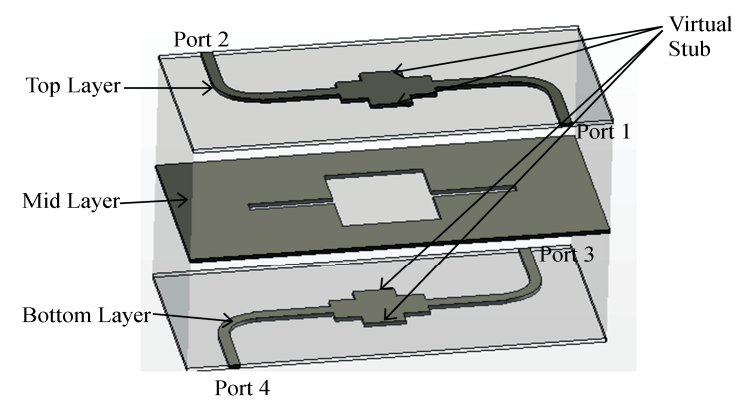

Fig. 2. The generated CST layout of the rectangular-shaped coupler with virtual short stub at top and bottom layer.

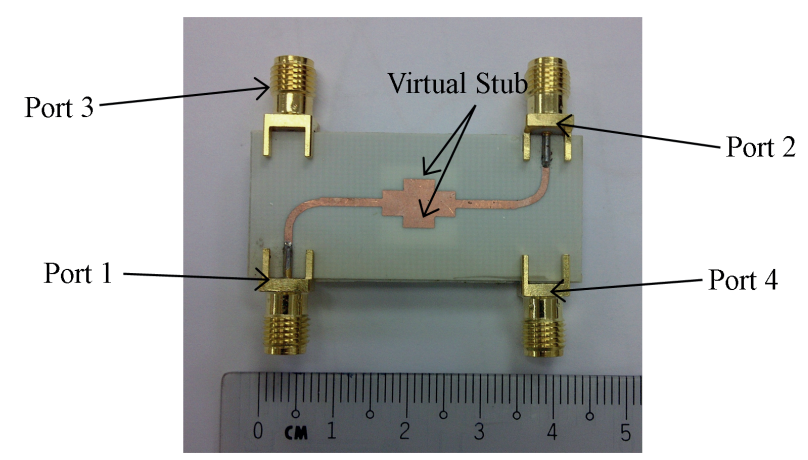

Fig. 3. The prototype of rectangular-shaped coupler with virtual short stubs, which operate from 2 to $6 \mathrm{GHz}$ band. width. As for the desired operating frequency, a key to meet this goal is by controlling the length of the microstrip and slotline. The simulated coupling and through coefficient are approximately around $3 \mathrm{~dB}$ from 2 to $6 \mathrm{GHz}$. Meanwhile, simulated return loss and isolation demonstrated good performance, which are better than $20 \mathrm{~dB}$ across this designated frequency band compared to the initial coupler, which is $15 \mathrm{~dB}$. Whereas, the measurement results of coupling and through coefficient show deviation of $\pm 1 \mathrm{~dB}$ from the ideal value of $3 \mathrm{~dB}$. At least 17 and $18 \mathrm{~dB}$ are depicted by the performance of measured return loss and isolation, respectively. The simulated phase difference between two output ports is $90^{\circ} \pm 1^{\circ}$. Whilst, the fabricated coupler exhibits slightly deviated phase difference from the simulated result with $90^{\circ} \pm 3^{\circ}$.

The appearance of stubs improves the performance of return loss and isolation. This significant improvement of return loss and isolation is possibly contributed by the smoother impedance transitions in this multi-section coupler configuration. Therefore, the losses contributed by the sharp edge of rectangular shape can be compensated by this proposed use of virtual short stubs in coupler design. In addition to that, the stubs connected at the microstrip patches will enforce the maximum electromagnetic power flow through the coupling slotline resulting of better return loss and isolation. This rectangular-shaped coupler is expected to have better degree of freedom in fabrication stage with limited facility.

The next concerned component in multi-port network shown in Fig. 1 (b) is 3-dB in-phase power divider. Fig. 4 and 5 show the configuration of the designed power divider with circular-shaped of tuning stubs and its fabricated prototype, respectively. They are formed by three conductive layers together with two substrate layers, where the substrate layers are placed in between the conductive layer. The middle layer of the common ground plane employs a narrow slotline to guide the input signal to the two output ports. In-phase outputs can be achieved by positioning the output ports to be in the same direction.

The key factors in multilayer microstrip-slot power divider design are the dimension of slotline at ground plane and chosen stubs terminating the microstrips and slotlines. The length of slotline at the ground plane is designed at the centre frequency of $4 \mathrm{GHz}$ with effective electrical length of $90^{\circ}$, which correspond to quarter wavelength. This chosen length of slotline is expected to allow the desired wideband frequency range from 2 to $6 \mathrm{GHz}$ to be achieved.

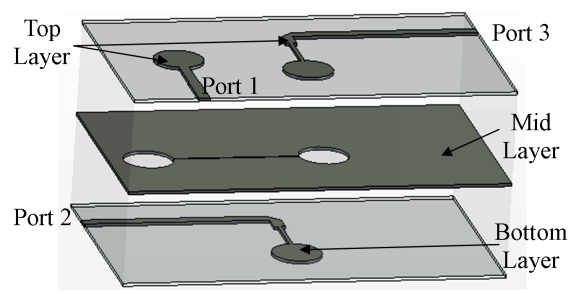

Fig. 4. The generated CST layout of the power divider with circular tuning stubs. 


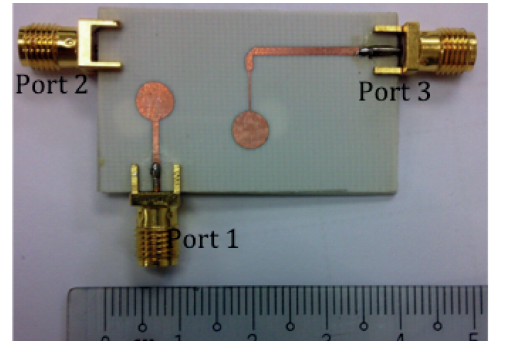

Fig. 5. The prototype of the power divider, which operate between 2 and $6 \mathrm{GHz}$ band.

As the design involves the transition from microstrip (input port) to slotline and slotline to microstrip (output ports), these lines cannot be left open-ended. Proper termination or stub must be chosen to terminate each of microstrip and slotline. Particularly, circular-shaped stub is chosen. Where, the size of stub controls the operating frequency of the designed power divider. The microstrip stub works as a short circuit, which can be named as a virtual short stub. While, slot stub acts as an open circuit, which then can be noted as a virtual open stub.

The simulated outputs at Port 2 and 3 of the power divider are $-3 \mathrm{~dB} \pm 1 \mathrm{~dB}$. Meanwhile, the measured per-

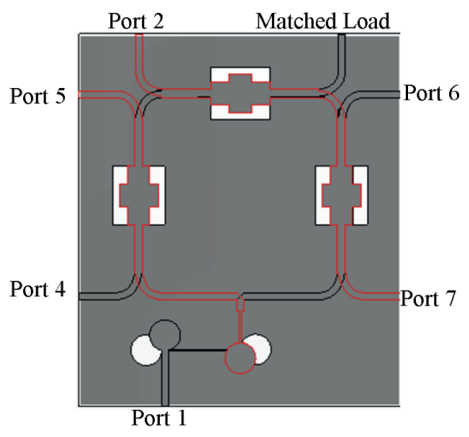

(a)

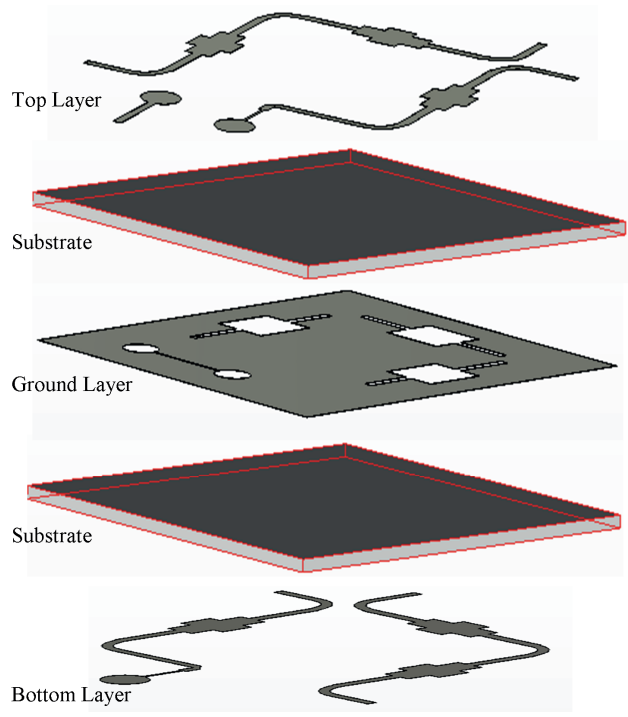

(b)

Fig. 6. (a) The overall layout of the multi-port and (b) its detailed layout for each layer of microstrip patches, substrates and slotlines. formances show slightly higher deviation of $\pm 2 \mathrm{~dB}$. Both performances depict agreeable low amplitude imbalance of the power divider at output ports. Comparable return losses are demonstrated by both simulation and measurement, which are better than $10 \mathrm{~dB}$. Meanwhile, slight deviation of measured characteristic of phase difference between the output ports is obtained with $\pm 4^{\circ}$ compared to simulated performance, which demonstrated almost $0^{\circ}$.

Then, the designed 3-dB quadrature couplers with the additional virtual stub and in-phase power divider with equal power division are applied to form the multi-port network. The symmetry arrangement of components is used to form this multi-port. Overall layout generated by CST Microwave Studio of multi-port is shown in Fig. 6(a). The red line shows the microstrip at the bottom layer, while the black line shows the microstrip at the top layer. The detailed layout for each layer is presented in Fig. 6(b). The lengths of microstrip lines connecting the components are taken into consideration in the design. The optimum length of the microstrip line must be used to minimize the effect of losses and to ensure well performance of phase characteristics. As this design has a multilayer structure, which consist of the slotlines at middle layer to broadside couple the top and bottom layer of microstrip patches, misalignment must be avoided

\section{S-Parameters and Phase Characteristics of Multi-Port Network}

This multi-port is then fabricated using wet etching technique in-house. The prototype of the multi-port is shown in Fig. 7. This prototype of multi-port is using two double-sided Rogers RO4003C substrates. These two substrates are affixed to minimize the existence of the air gap between them. This multi-port has an overall dimension of $54 \mathrm{~mm} \times 62 \mathrm{~mm}$ excluding SMA connectors, which can be considered compact in size.

The simulated and measured S-parameters are plotted in Fig. 8 to 11. At Port 1, the simulated and measured magnitudes of reflection coefficients demonstrate quite similar performance, where both are less than $-10 \mathrm{~dB}$. Meanwhile,

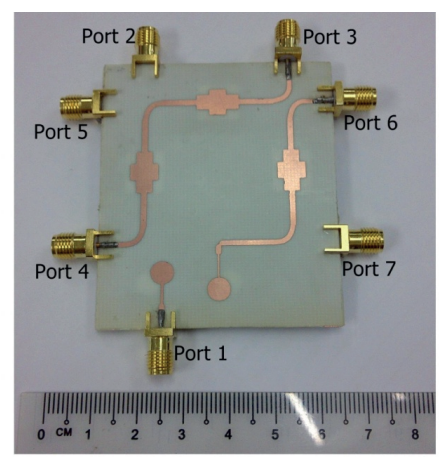

Fig. 7. Prototype of the fabricated multi-port with the attached SMA connectors 
the simulated reflection coefficient at Port 2 is better than Port 1 , which is less than $-15 \mathrm{~dB}$. However, the measurement result shows that reflection coefficient magnitude at Port 2 is only $-10 \mathrm{~dB}$, which is similar to the result obtained at Port 1 . The mid frequency range exhibits the most optimal reflection coefficients at both Port 1 and 2 .

The next verification is concerning the characteristics of transmission coefficients, $S_{i j}$ where $i=4,5,6,7$ and $j=1,2$. In the ideal manner, the information signal splits equally at the output ports (Port 4, 5, 6, 7). Therefore, $S_{i j}$ are equal to $-6 \mathrm{~dB}\left(\left|S_{\mathrm{i} 1}\right|=\left|S_{\mathrm{i} 2}\right|=0.5\right.$ or $\left.-6 \mathrm{~dB}\right)$. The responses of simulated and measured transmission coefficients, $S_{i j}$ are plotted in Fig. 9. From the observation, the simulated values for transmission coefficients are $-6 \pm 2 \mathrm{~dB}$. Whilst, the measured values show more deviation, which are $-6 \pm 4 \mathrm{~dB}$ across the designated frequency band of 2 to $6 \mathrm{GHz}$.

Then, as the multi-port has demonstrated agreeable simulated and measured performances of the reflection and transmission coefficients, the next assessment of multi-port concerns its phase characteristics. Fig. 10 and 11 depict the phase characteristic performance of multi-port, which are summarized in Tab. 2 and 3. The phase of $S_{i j}$, where $i=4$,

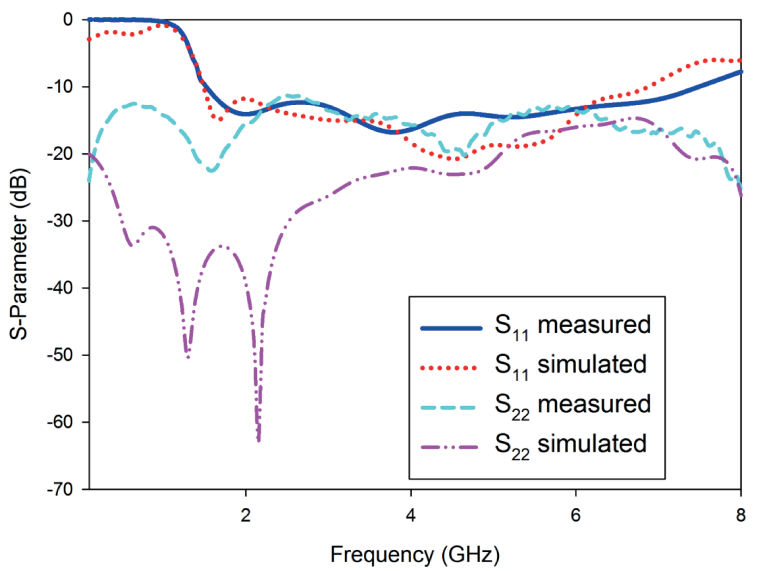

Fig. 8. The simulated and measured $S_{11}$ and $S_{22}$ of the proposed multi-port.

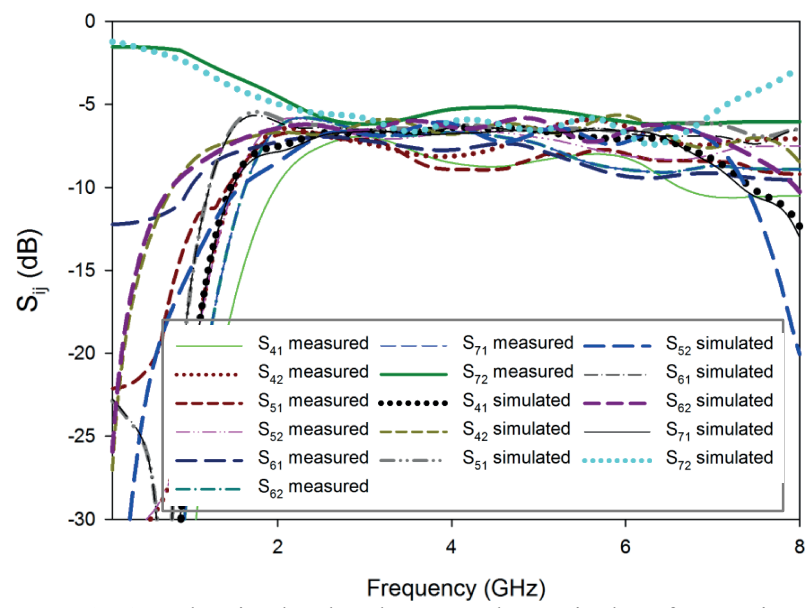

Fig. 9. The simulated and measured magnitudes of transmission coefficients, $S_{i j}$ of the proposed multi-port (where $i=4,5,6,7$ and $j=1,2$ ).

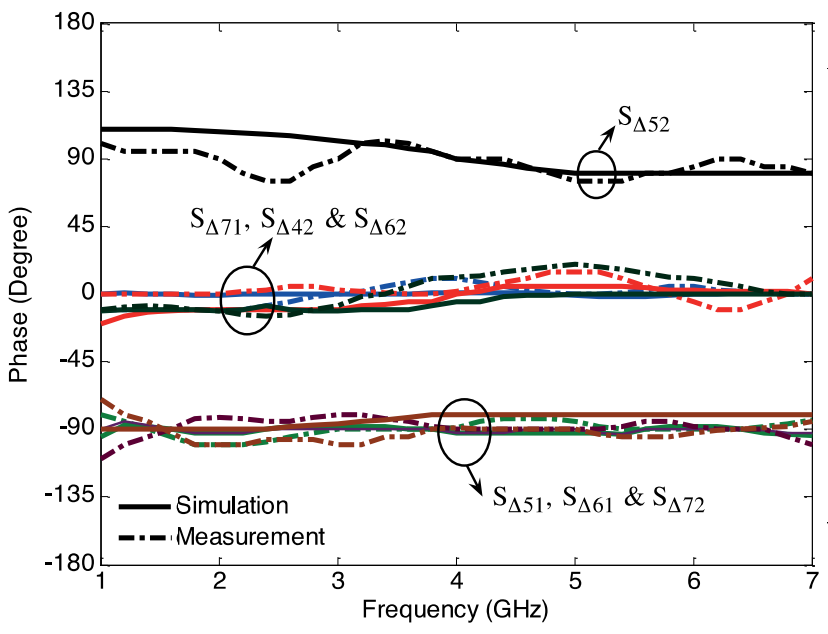

Fig. 10. The simulated and measured phase characteristics $\left(S_{\Delta i j}\right)$ of multi-port network, which is referenced to phase $S_{41}$ (where $i=4,5,6,7$ and $j=1,2$ )

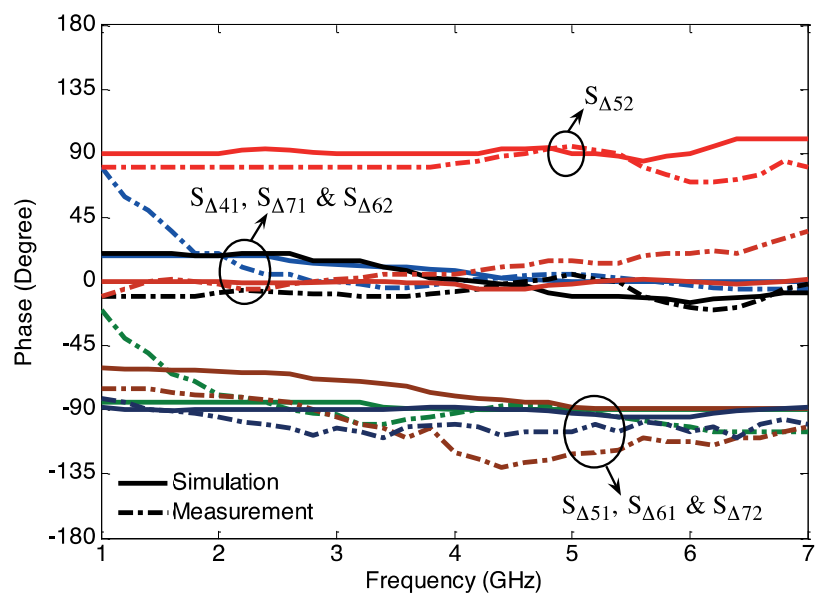

Fig. 11. The simulated and measured phase characteristics $\left(S_{\Delta i j}\right)$ of multi-port network, which is referenced to phase $S_{42}$ (where $i=4,5,6,7$ and $j=1,2$ ).

\begin{tabular}{|c|c|c|c|c|c|c|c|}
\hline \multirow{2}{*}{ Parameter } & \multicolumn{7}{|c|}{ Phase $\left(S_{\Delta i j}\right)$} \\
\cline { 2 - 8 } & $S_{\Delta 51}$ & $S_{\Delta 61}$ & $S_{\Delta 71}$ & $S_{\Delta 42}$ & $S_{\Delta 52}$ & $S_{\Delta 62}$ & $S_{\Delta 72}$ \\
\hline Ideal & $-90^{\circ}$ & $-90^{\circ}$ & $0^{\circ}$ & $0^{\circ}$ & $90^{\circ}$ & $0^{\circ}$ & $-90^{\circ}$ \\
\hline Simulation & $\pm 3^{\circ}$ & $\pm 3^{\circ}$ & $\pm 2^{\circ}$ & $\pm 10^{\circ}$ & $\pm 15^{\circ}$ & $\pm 10^{\circ}$ & $\pm 8^{\circ}$ \\
\hline Measurement & $\pm 10^{\circ}$ & $\pm 8^{\circ}$ & $\pm 10^{\circ}$ & $\pm 15^{\circ}$ & $\pm 15^{\circ}$ & $\pm 20^{\circ}$ & $\pm 10^{\circ}$ \\
\hline
\end{tabular}

Tab. 2. Deviation comparison of the multi-port network phase characteristics $\left(S_{\Delta i j}\right)$, which is referenced to phase $S_{41}$ (where $i=4,5,6,7$ and $j=1,2$ ) from 2 to $6 \mathrm{GHz}$.

\begin{tabular}{|c|c|c|c|c|c|c|c|}
\hline \multirow{2}{*}{ Parameter } & \multicolumn{7}{|c|}{ Phase $\left(S_{\Delta i j}\right)$} \\
\cline { 2 - 8 } & $S_{\Delta 41}$ & $S_{\Delta 51}$ & $S_{\Delta 61}$ & $S_{\Delta 71}$ & $S_{\Delta 52}$ & $S_{\Delta 62}$ & $S_{\Delta 72}$ \\
\hline Ideal & $0^{\circ}$ & $-90^{\circ}$ & $-90^{\circ}$ & $0^{\circ}$ & $90^{\circ}$ & $0^{\circ}$ & $-90^{\circ}$ \\
\hline Simulation & $\pm 18^{\circ}$ & $\pm 5^{\circ}$ & $\pm 20^{\circ}$ & $\pm 20^{\circ}$ & $\pm 4^{\circ}$ & $\pm 5^{\circ}$ & $\pm 5^{\circ}$ \\
\hline Measurement & $\pm 20^{\circ}$ & $\pm 11^{\circ}$ & $\pm 29^{\circ}$ & $\pm 18^{\circ}$ & $\pm 15^{\circ}$ & $\pm 20^{\circ}$ & $\pm 18^{\circ}$ \\
\hline
\end{tabular}

Tab. 3. Deviation comparison of the multi-port network phase characteristics $\left(S_{\Delta i j}\right)$, which is referenced to phase $S_{42}$ (where $i=4,5,6,7$ and $j=1,2$ ) from 2 to $6 \mathrm{GHz}$.

5, 6 and 7, and $j=1$ and 2 are presented by referring to phase of $\mathrm{S}_{41}$ and $\mathrm{S}_{42}$. Ideally, the phase characteristics are approximately constant at $0^{\circ}, 90^{\circ}$ or $-90^{\circ}$. This can be explained by the characteristic of the designed coupler with 
$90^{\circ}$ phase difference between output ports. While, the power divider offers $0^{\circ}$ phase difference.

Through the observation on the simulated and measured phase characteristics of multi-port shown in Fig. 10 to 11 and the summarized deviation in Tab. 2 to 3 , the measured phase characteristics have deviated more compared to the simulation especially for the $S_{\Delta 62}$ with $\pm 20^{\circ}$ when $S_{41}$ is used as reference and $S_{\Delta 61}$ with $\pm 29^{\circ}$ when $S_{42}$ is used as reference. This degradation can be due to misalignment of the microstrips and slotlines during fabrication and the existence of the air gap between two substrates. Producing the prototype via more efficient fabrication technique, which is offered from industry, can reduce these errors.

\section{QPSK Modulation Results}

Then, the design of multi-port in CST MWS is converted to TouchStone file. This file is later exported to represent the design of multi-port network in ADS. A schematic of QPSK modulator is fixed in ADS by referring to Fig. 1 with the connection of each modulation state as indicated in Tab. 1. Referring to Tab. 1, when modulation state, $m$ equal to 0 , all output ports are connected to the open termination. While, when modulation state, $m$ equal to 3, all output ports are shorted. Fig. 12 shows the QPSK modulation response, $S_{2}$ for all modulation states in a complex polar form, which simulated in ADS software between 2 and $6 \mathrm{GHz}$ with the use of modulation state 0 as reference. It can be noted, the modulation responses from simulation present average magnitude of one with tolerance of \pm 0.3 . Meanwhile, the phase characteristics are approximately around $0^{\circ}, 90^{\circ},-90^{\circ}$ and $180^{\circ}$ with deviation around $20^{\circ}$ from the stated ideal value.

Then, the presented good performance of simulated QPSK modulator is verified practically in the laboratory. The measurement setup by referring the configuration in Fig. 1(a) is shown in Fig. 13. In order to investigate the wideband performance of modulated signal $\left(S_{2}\right)$, it can be realized by measuring the transmission coefficient of $S_{21}$. Therefore, Port 1 and 2 are connected to the vector net-

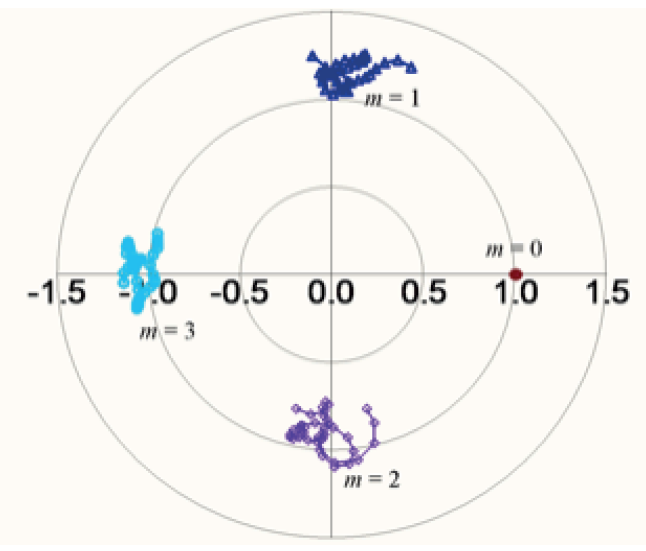

Fig. 12. Simulated QPSK constellation of the proposed QPSK modulator using multi-port network from 2 to $6 \mathrm{GHz}$.

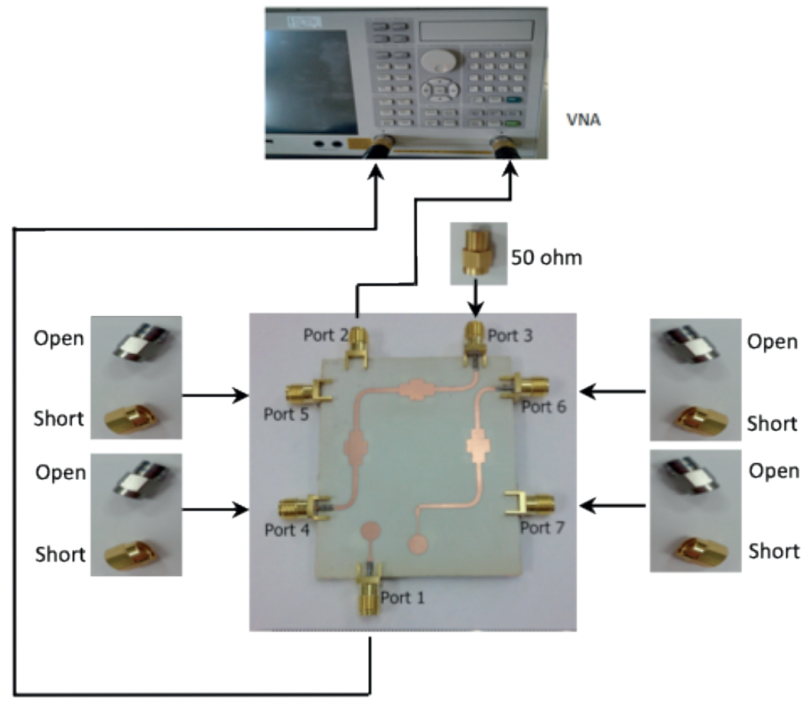

Fig. 13. The measurement setup of QPSK modulator using multi-port network.

work analyzer (VNA). Meanwhile, Port 3 and output ports are terminated with $50 \mathrm{ohm}$, and short or open load, respectively.

The measured QPSK constellation is presented in Fig. 14. It is shown that the magnitudes of $S_{2}$ are slightly changing in average of 0.8 with higher phase deviation especially for modulation state, $m$ equal to 3 , the phase deviation is less than $45^{\circ}$ which is the worst deviation. Meanwhile, other modulation states deviated in range less than $30^{\circ}$. However, the constellation still shows the phase differs by $90^{\circ}$ in average from each modulation state.

Then, by concerning the operation as a modulator in communication application, the proposed design is compared to the other related and published works in [3-7]. The comparison is not considering the designs with operating frequency greater than $10 \mathrm{GHz}$. By referring to Tab. 4, the proposed design has the broadest bandwidth of $100 \%$ with comparable small size as the design in [7]. Hence, the implementation of multilayer microstrip-slot

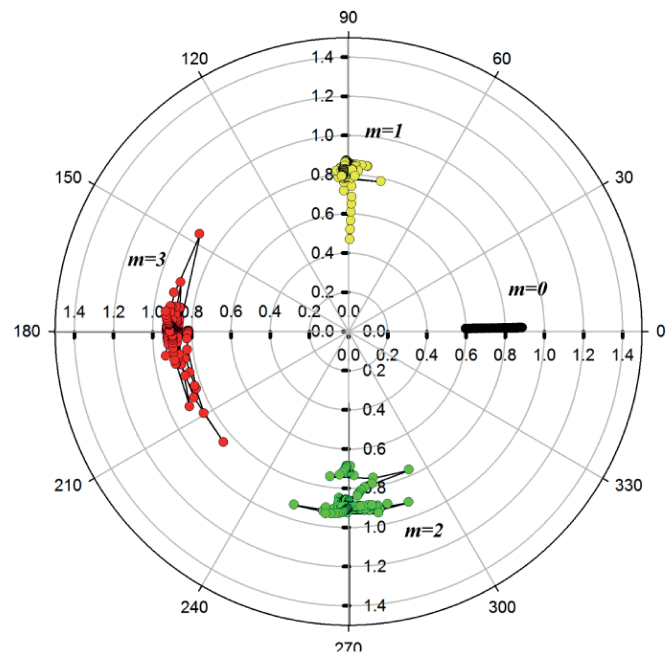

Fig. 14. Measured QPSK constellation of the proposed QPSK modulator using multi-port from 2 to $6 \mathrm{GHz}$. 


\begin{tabular}{|c|c|c|c|c|}
\hline Design & Configuration & $\begin{array}{c}\text { Size } \\
(\mathrm{mm} \times \mathrm{mm})\end{array}$ & $\begin{array}{l}\text { Operating } \\
\text { frequency }\end{array}$ & $\% \mathrm{BW}$ \\
\hline $\begin{array}{c}\text { Proposed } \\
\text { design }\end{array}$ & $\begin{array}{c}\text { Multilayer microstrip- } \\
\text { slot coupler and } \\
\text { divider }\end{array}$ & $54 \times 62$ & $2-6 \mathrm{GHz}$ & $100 \%$ \\
\hline [3] & \begin{tabular}{|c|} 
Branch-line coupler \\
and Wilkinson power \\
divider
\end{tabular} & $\begin{array}{c}\begin{array}{c}\text { Not } \\
\text { specified } \\
\text { (larger) }\end{array} \\
\end{array}$ & $2.5 \mathrm{GHz}$ & $40 \%$ \\
\hline [4] & \begin{tabular}{|c|} 
Branch-line coupler \\
and Wilkinson power \\
divider \\
\end{tabular} & $\begin{array}{c}\begin{array}{c}\text { Not } \\
\text { specified } \\
\text { (larger) }\end{array} \\
\end{array}$ & $7.5 \mathrm{GHz}$ & $13 \%$ \\
\hline [5] & \begin{tabular}{|c|} 
Branch-line coupler \\
with impedance stubs \\
and Wilkinson power \\
divider \\
\end{tabular} & $\begin{array}{c}95 \times 120 \\
\text { (transmitter) }\end{array}$ & $\begin{array}{c}3.1-4.8 \\
\mathrm{GHz}\end{array}$ & $43 \%$ \\
\hline [6] & $\begin{array}{c}\text { Multilayer coupler and } \\
\text { Wilkinson power } \\
\text { divider }\end{array}$ & $\begin{array}{c}\text { Not } \\
\text { specified } \\
\text { (small) }\end{array}$ & $3-5 \mathrm{GHz}$ & $50 \%$ \\
\hline [7] & $\begin{array}{l}\text { Two-stage Wilkinson } \\
\text { power divider, and } \\
\text { elliptical disk coupler } \\
\text { or broadside-coupled } \\
\text { microstrip-CPW }\end{array}$ & $\approx 50 \times 70$ & $4.5-9 \mathrm{GHz}$ & $67 \%$ \\
\hline
\end{tabular}

* BW $=$ Bandwidth

Tab. 4. Comparison of the proposed design with the related and published works in [3-7].

technology in the design has realized the goal of wideband multi-port for the modulation purpose of the quadrature phase shift keying (QPSK).

\section{Conclusion}

A wideband QPSK modulator has been presented by implementing multi-port network that can perform from 2 to $6 \mathrm{GHz}$. The used multi-port network for this QPSK modulator has been formed by $3-\mathrm{dB}$ rectangular-shaped couplers with virtual short stubs and in-phase power divider with equal power division in multilayer microstripslot technology. The multi-port has approximately $-6 \mathrm{~dB}$ transmission coefficients with very good performance of reflection coefficients at Port 1 and 2 . The phase characteristics of $0^{\circ}, 90^{\circ}$ or $-90^{\circ}$ have been obtained with the worst deviation of $\pm 29^{\circ}$. Well performing wideband QPSK modulator has been accomplished through the combination of switchable connected short and open load termination at four designated output ports. Comparable performance has been depicted from the presented QPSK constellations in the complex polar plane for both simulation and measurement. All measured modulation states have shown average magnitudes of 0.8 . While, the highest phase deviation of $\pm 45^{\circ}$ can be noted from the measured QPSK constellation for the third modulation state $(m=3)$ compared to the simulated phase of $\pm 20^{\circ}$. It contributed from the phase characteristics of multi-port for each transmission coefficient, $S_{i j}$ and the use of non-ideal SMA connectors and terminations. This deviation can be corrected through a simple error correction algorithm, which not included in this article. This relatively small size design has greater than $33 \%$ bandwidth compared to the work in [7]. The wideband modulator can be applied in wireless communication applications without biasing circuit, which appar- ently lessen the design complexity and appropriate for any modern gadgets such as tablet and notebook.

\section{Acknowledgments}

The authors acknowledge the financial assistance from Ministry of Education Malaysia (MOE) and Universiti Teknologi Malaysia (UTM) via Fundamental Research Grant Scheme (FRGS) Research University Grant (RUG) with Vote Number of 4F206 and 05H43, respectively.

\section{References}

[1] WANG, C. H., CHANG, H. Y., WU, P.S., et al. A $60 \mathrm{GHz}$ lowpower six-port transceiver for gigabit software-defined transceiver applications. In Proceedings of the IEEE International Solid-State Circuits Conference. San Francisco (USA), 2007, p. 192-196. DOI: 10.1109/ISSCC.2007.373359

[2] LIM, H. S., KIM, W. K., YU, J. W., et al. Compact six-port transceiver for time duplex systems. IEEE Microwave and Wireless Components Letters, 2007, vol. 17, no. 5, p. 394-396. ISSN: 1531-1309. DOI: 10.1109/LMWC.2007.895731

[3] ÖSTH, J., KARLSSON, M., SERBAN, A., GONG, S. M-QAM six-port modulator using only binary baseband data, electrical or optical. IEEE Transactions on Microwave Theory and Techniques, 2013, vol. 61, no. 6, p. 2506-2513. ISSN: 0018-9480. DOI: 10.1109/TMTT.2013.2259255

[4] ÖSTH, J., SERBAN, A., OWAIS, M. K., et al. Six-port gigabit demodulator. IEEE Transactions on Microwave Theory and Techniques, 2011, vol. 59 no. 1, p. 125-131. ISSN: 0018-9480. DOI: 10.1109/TMTT.2010.2091198

[5] HAKANSSON, P., GONG, S. Ultra-wideband six-port transmitter and receiver pair 3.1-4.8 GHz. In Proceedings of the Asia Pacific Microwave Conference (APMC). Hong Kong (China), 2008, 4 p. DOI: $10.1109 /$ APMC.2008.4958318

[6] ABIElmona, S., NGUYEN, H. V., CAlOZ, C., et al. Compact multilayer ultra-wideband six-port device for modulation/demodulation. Electronics Letters, 2007, vol. 43, no. 15, p. 813-814. ISSN: 0013-5194. DOI: 10.1049/el:20070678

[7] IBRAHIM, S. Z., ABBOSH, A. M., ANTONIADES, M. A. Direct quadrature phase shift keying modulation using compact wideband six-port networks. IET Microwaves, Antennas \& Propagation, 2012, vol. 6, no. 8, p. 854-861. ISSN: 1751-8725. DOI: 10.1049/iet-map.2012.0010

[8] TATU, S. O., MOLdOVAN, E., WU, K., BOSISIO, R. G. A new direct millimeter-wave six-port receiver. IEEE Transactions on Microwave Theory and Techniques, 2001, vol. 49, no. 12, p. 2517 to 2522. ISSN: 0018-9480. DOI: $10.1109 / 22.971644$

[9] TATU, S. O., MOLDOVAN, E., BREHM, G., et al. Ka band direct digital receiver. IEEE Transactions on Microwave Theory and Techniques, 2002, vol. 50, no. 11, p. 2436-2442. ISSN: 00189480. DOI: 10.1109/TMTT.2002.804646

[10] XU, S., LIU, F. L. Multi-target detection in FMCW radar based on six-port technology. In Proceedings of the Joint 31st International Conference on Infrared Milimeter Waves and 14th International Conference on Teraherz Electronics. Shanghai (China), 2006. DOI: 10.1109/ICIMW.2006.368516 
[11] GHAZALI, S. N. A. M., SEMAN, N., RAHIM, M. K. A., et al. Design of wideband rectangular-shaped coupler with virtual short stubs for wireless communication applications. Wireless Personal Communications, 2013, vol. 73, no. 3, p. 1331-1342. ISSN: 09296212. DOI 10.1007/s11277-013-1280-z

[12] SEMAN, N., BIALKOWSKI, M. E. Design and analysis of an ultra wideband three-section microstrip-slot coupler. Microwave and Optical Technology Letters, 2009, vol. 51, no. 8, p. 1889 to 1892. DOI: $10.1002 /$ mop.24484. ISSN: 0895-2477

\section{About the Authors ...}

Norhudah SEMAN received the B.Eng. in Electrical Engineering (Telecommunications) degree from the Universiti Teknologi Malaysia, Johor, Malaysia, in 2003 and M.Eng. degree in RF/Microwave Communications from
The University of Queensland, Brisbane, St. Lucia, Qld., Australia, in 2005. In September 2009, she completed her Ph.D. degree at The University of Queensland. In 2003, she was an Engineer with Motorola Technology, Penang, Malaysia, where she was involved with the RF and microwave components design and testing. Currently, she is a Senior Lecturer in Wireless Communication Centre (WCC), Universiti Teknologi Malaysia. Her research interests concern the design of microwave circuits for biomedical and industrial applications, UWB technologies, and mobile communications.

Siti Nor Ain MOHAMED GHAZALI obtained her first degree from Universiti Teknologi Malaysia majoring in Electrical Engineering (Telecommunication) in 2010. In 2014, she received her M.Sc degree in Electrical Engineering. 